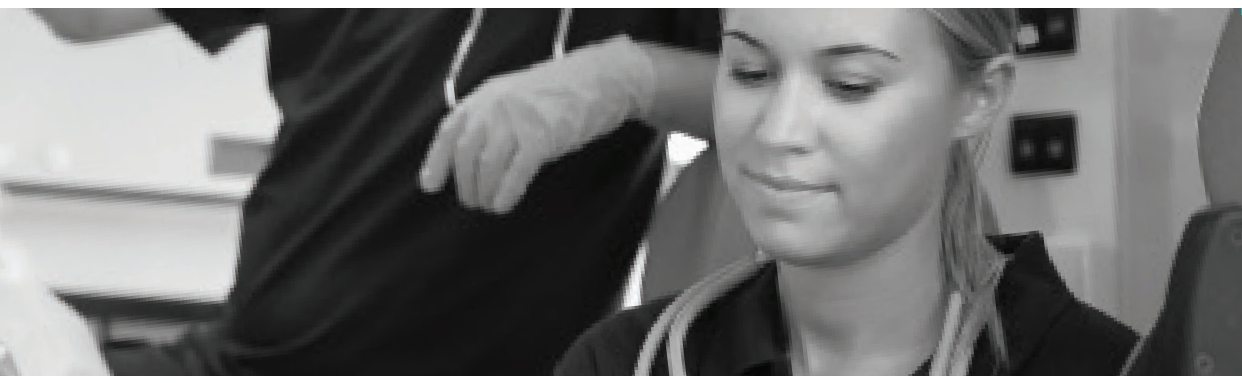

Volume 13 | Issue 4 | Article 5

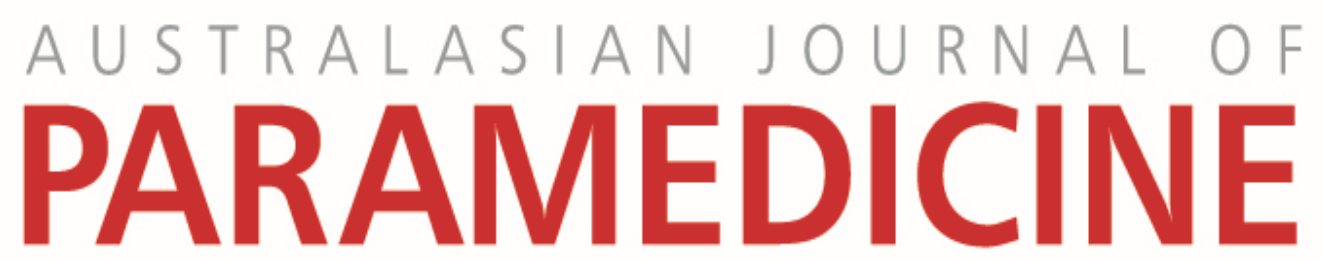

PARAMEDICS

AUSTRALASIA

Paramedic diagnosis of acute coronary syndrome in the out-of-hospital patient with acute, non-traumatic chest pain: The RSVP ${ }_{3}$ HEART exam

Marc Colbeck

Australian Catholic University, Brisbane, Queensland 


\section{Paramedic diagnosis of acute coronary syndrome in the out-of-hospital patient with acute, non-traumatic chest pain: The RSVP ${ }_{3}$ HEART exam}

Marc Colbeck $\mathrm{CCP}, \mathrm{PhD}(\mathrm{c})$ is a Critical Care Paramedic, Senior Lecturer, Course Coordinator and candidate for a PhD in medicine ${ }^{1}$

Affiliation:

${ }^{1}$ Australian Catholic University, Brisbane, Queensland

\section{Abstract}

\section{Background}

The accurate diagnosis of acute coronary syndrome in the out-of-hospital patient experiencing acute, not-traumatic chest pain remains an important challenge both clinically and financially. As both a high frequency and high impact occurrence, it is rightly considered to be a high-risk situation.

\section{Methods}

In order to recommend an evidence-based approach to paramedic diagnosis of this condition, the author conducted a scoping study, reviewing over 70 sources relevant to the topic from 1984 to 2015, and then summarised the findings.

\section{Results}

The evidence suggests that most of the current methods taught to paramedics to identify acute coronary syndrome patients are not in accord with findings that have been reported in the literature over the past 20 years. Areas where current teaching is not in accord with the evidence are highlighted, traditionally taught assessments that are non-diagnostic are identified, and those that are most diagnostic are listed and explained.

\section{Conclusion}

Research suggests that paramedics follow the HEART assessment (History, EKG, Age, Risk factors, Troponin) and this work offers a novel, evidence-based method to assess the patient's history using the acronym RSVP ${ }_{3}$ (Radiation, Similarity, Variation, Pleuritic, Positional, Palpation), which is meant to replace other commonly used, but non-diagnostically sensitive, acronyms such as OPQRST, DOLOR, SOCRATES and CHEST PAIN. An emphasis is also placed on performing a thorough physical examination and so the novel mnemonic 'RSVP ${ }_{3}$ Heart Exam' is introduced. Evidence to support these recommendations is given.

\section{Keywords:}

diagnosis; acute coronary syndrome; ACS; paramedic; chest pain 


\section{Background}

Cardiovascular disease is the largest single killer of Australians (1). Patients who present to Australian emergency rooms (ER) with acute, non-traumatic chest pain (ANTCP) that may be of myocardial origin are one of the most common categories of visitors to the ER, accounting for approximately $5-10 \%$ of all ER visits (1). Of these patients, $75-85 \%$ will ultimately be found not to have acute coronary syndrome (ACS) (1). The cost of testing this cohort of non-ACS patients has not been precisely quantified, but there is reason to believe it would be significant. One study (2) found that the total cost of ACS evaluation and treatment in Australia from 2008-2009 was approximately $\$ 7.6$ billion AUD. A 1984 study from the United States (3) found that (over 20 years ago) performing testing on patients to 'rule out' ACS resulted in an estimated cost to the health care system of $\$ 8$ billion USD annually. Clearly, this is a diagnosis for which clinicians need to increase accuracy.

\section{Implications for paramedics}

Rapid transport and/or treatment for true ACS is important in minimising myocardial damage (4) and improving patient morbidity and mortality outcomes (5-7). Hence the common admonition that 'time is muscle'.

Rapid transport for non-ACS chest pain is not essential unless there are other life-threatening conditions present that merit the hazard to the public (and paramedics) that driving using lights and sirens through traffic entails. Paramedics have a high work-related injury rate (80 cases per 1000 workers per year), and injuries from road traffic accidents are twice as common as injuries from being assaulted (8).

Intuitively, the less often paramedics use their lights and sirens in traffic, the less likely they are to have a traffic accident; and the less paramedics use their sirens, the less stressful it is on their patients. Therefore it would be useful to determine which patients with ANTCP are at low risk for ACS in order to minimise risk and distress by transporting patients without lights and sirens.

\section{Aims}

This paper provides an overview of which signs and symptoms are most effective in identifying ACS in the ANTCP patient. Additionally, the author suggests future areas of research that could help improve paramedic diagnostic knowledge and ability in this area

\section{Methods}

A scoping survey consisting of an iterative process of divergent exploration of the literature to the point of exhaustion of new findings, with a subsequent convergent analysis of reports was performed to identify and summarise the findings of over 70 relevant peer-reviewed papers.

\section{Results}

\section{Existing diagnostic protocols}

Although physicians who use an unstructured diagnostic strategy perform better than random in diagnosing ACS in the $\mathrm{ER}$, they do no better than their residents, and their predictions are neither sensitive nor specific (9). Furthermore, one study suggests that this limited ability to diagnose ACS seems to be true regardless of clinical specialty (10).

In an effort to improve their accuracy at diagnosing ACS, physicians have developed several diagnostic scoring tools. Overviews of these can be found in the following papers (11-13). In order for a diagnostic scoring tool to be widely adopted it needs to have a specificity and sensitivity that would reassure clinicians of its effectiveness. Surveys of (primarily American) doctors show that they consider a more than $1 \%$ error rate in discharging patients to be unacceptable, although this may be a number influenced by the litigious culture of American emergency medicine $(14,15)$. None of the diagnostic scoring tools which have been developed can perform consistently to this level, though one (the HEART tool, discussed later) does come close.

Furthermore, reviews of many of these tools have shown methodological weaknesses in their development that could have led to the introduction of bias, and suggested that none of the examined tools were appropriately powerful to be recommended for clinical use (11). To date, none have reached widespread acceptance.

Nonetheless, the structure of these tools gives clinicians an idea of the types of clinical interview questions that researchers have considered most valuable to focus on. Hess (11) lists over 64 complaints and findings that researchers have assessed for their ability to rule in or rule out ACS in the patient with ANTCP.

\section{Patient assessment}

The first statement of what medical professionals call 'typical' (of ACS) chest pain was offered by Dr. William Heberden $(16,17)$ in 1768 , who described a painful sensation in the breast, with a 'strangling' sensation, anxiety and radiation of pain to the left arm, which was often provoked by exertion and palliated by rest. This is essentially the description still taught to most paramedics today.

What is, or is not a 'high yield' assessment to determine ACS in the ANTCP patient has been extensively studied over the past several decades. Despite suggestions that a good mnemonicbased assessment will help identify ACS, such as OPQRST, DOLOR or CHEST PAIN (18), the reported patient history on its own has consistently demonstrated a very poor ability to allow a clinician to rule out ACS (19-25) and there is no support for the effectiveness of any of the commonly used assessment mnemonics. Therefore, paramedics require an evidence-based approach to the assessment of the ANTCP patient. 
In this section of the paper the following 16 common areas of assessment of the ANTCP patient will be examined:
1. Age
2. Risk factors
3. Obesity
4. Diagnostic value of glyceryl trinitrate (GTN)
5. Quality of pain
6. Location of pain
7. Radiation of pain
8. Intensity of pain
9. Ethnicity
10.Associated symptoms: nausea, vomiting and sweating
11. Dyspnoea
12. Dizziness
13. Gender
14. Physical examination
15. Electrocardiogram (ECG) changes
16. Troponin.

\section{A brief diversion: Likelihood ratios}

In order to quantify and understand the results of the effectiveness of various signs and symptoms that have been studied, it is important to understand what a 'likelihood ratio' $(L R)$ is and how to interpret a LR score. After a brief explanation of likelihood ratios, they will be used to quantify the effectiveness of the 16 listed standard assessments for ANTCP.

A Likelihood Ratio (LR) is the likelihood that a given test result (either positive or negative) would be expected in a patient with the target disorder compared to the likelihood that that same result would be expected in a patient without the target disorder.

A LR value of 1 means there's no diagnostic value in performing the test as it won't help rule in or rule out the disease either way. Usually, values from 0.5-2 aren't considered to be helpful diagnostically.

Likelihood ratios from 2-5 suggest a small probability of a disease actually being there if the test says it is. From 5 to 10 there is a moderate probability of the test being correct. ALR above 10 is considered a large probability and often translates clinically as 'ruling in' the disease.

Similarly, for values less than 1 , the smaller the likelihood ratio, the greater the decrease in probability. Clinically, a score less than 0.1 is considered to 'rule out' the disease (27), see Figure 1.

\begin{tabular}{|c|c|c|c|c|c|c|}
\hline $\begin{array}{c}<.1 \\
\text { 'rule } \\
\text { out' }\end{array}$ & $\begin{array}{c}\text { Moderately } \\
\text { unlikely }\end{array}$ & $\begin{array}{c}0.2-0.5 \\
?\end{array}$ & $\begin{array}{c}0.5-2 \\
\text { Useless }\end{array}$ & $\begin{array}{c}2-5 \\
?\end{array}$ & $\begin{array}{c}5-10 \\
\text { Moderately } \\
\text { likely }\end{array}$ & $\begin{array}{c}>10 \\
\text { 'rule in' }\end{array}$ \\
\hline
\end{tabular}

Figure 1. Clinical value of likelihood ratios

\section{The 16 common areas of assessment of the ANTCP patient}

\section{Age}

Older patients are more likely to have ACS in the setting of ANTCP. Studies consistently show the importance of considering age during a diagnosis of chest pain, with one post hoc analysis (28) of over 10,000 patients showing that patients aged 75 years or more were twice (1.8 times) as likely to be having ACS in ANTCP than those aged less than 75 years.

Walker (29) and Marsan (30) showed that patients aged less than 40 years, with no known cardiac disease, with neither classic cardiac risk factors or an abnormal ECG and abnormalities of biomarkers at initial presentation, were unlikely to suffer a major adverse cardiac event (MACE) such as an acute myocardial infarction (AMI), cardiac surgery or cardiogenic shock within 30 days.

This is a common outcomes measurement referred to as the '30 day MACE', which will be used in this paper.

Another study (31) had similar findings, determining that patients aged 25-40 years, with a normal ECG and no history of prior ischaemic chest pain were unlikely to have a MACE within 30 days. This study also showed that patients aged 40 years or over with a normal ECG, no previous ischaemic chest pain, an unlikely history and symptoms for ischaemic chest pain and a normal or low creatine kinase-myocardial type isoenzyme that didn't increase over 2 hours were also unlikely to suffer a 30-day MACE. These findings were later corroborated by another independent prospective cohort study (32). 


\section{Risk factors}

Risk factors were originally derived from the Framingham study in the mid-to-late 1900s to determine the likelihood of a patient subsequently developing coronary artery disease in 5 and 10 years. They were never intended as an aid to help the physician rule in or out ACS in the ANTCP patient (12).

Despite this, once they were discovered, many clinicians assumed they could be used this way until subsequent research (33) showed they were not as clinically definitive as expected.

The following risk factors have been assessed and are presented in order of decreasing usefulness: Abnormal prior stress test [LR 3.1], peripheral arterial disease (PAD) [2.7], prior coronary artery disease (CAD) [2.0], prior myocardial infarction [1.6], diabetes [1.4], cerebrovascular disease [1.4], Male [1.3], hyperlipidaemia [1.3], hypertension [1.2], any tobacco use [1.1], obesity [1.0], prior coronary artery bypass graft (CABG) [0.97]. No risk factor, when absent, gave a likelihood of 0.5 or lower (22).

In an attempt to improve the predictive ability of assessing risk factors some researchers tried to combine them in order to study, for example, what the LR would be for a patient with 3-6 different risk factors. They found that the LR of a ANTCP patient with no history of CAD having ACS with 3-6 of the classic risk factors for $C A D$ is only 1.4 . For patients who have already been diagnosed with CAD the LR of having ACS in the presence of 3-6 risk factors actually falls to 1.10 (12). Therefore the risk factors with the highest yields - abnormal prior stress test, peripheral arterial disease, and prior coronary artery disease have all been included in the RSVP ${ }_{3}$ HEART Exam mnemonic.

\section{Obesity}

Body mass index (BMI) is not associated with a 30-day increase in MACE (34) and has a LR of exactly 1 (22). One would assume that a morbidly obese patient would be much more likely to be experiencing ACS, but the evidence shows that they aren't, and therefore BMI is of no use in ruling in, or out, ACS.

\section{Use of glyceryl trinitrate}

Another common belief is that if a patient's ANTCP is relieved by GTN then it is likely of cardiac origin. Contradicting this belief, several studies have shown there is no correlation between relief of NTCP with GTN and ACS or CAD (35-39) and has an unhelpful LR of 1.1 (22).

Therefore, seeing a patient experience relief (or not) from the administration of GTN offers no valid information as to whether or not they are (or are not) experiencing ACS. It is diagnostically useless.

However, it is critical to stress that diagnostically useless does not mean therapeutically useless. The administration of GTN is still a standard treatment for suspected ACS that should not be withheld from a patient who requires it.

\section{Quality of pain}

Some clinicians believe that the quality of a patient's pain can help suggest ACS and consequently use terms such as 'typical' and 'non-typical' (of ACS) chest pain (as initially suggested by Heberden in 1768). There is little research to support such broad categories and some that refutes it. There is a common dictum that 'the patient didn't read the book', meaning that they often (frustratingly, for clinicians) don't present in the way medical textbooks suggest they would. Ischaemic chest pain is a prime example of this. Instead of saying that they are experiencing a 'strangling' pressure or pain in their chest, about half of all patients with AMI report no pain at all, and almost a quarter describe something other than pain or pressure (eg. 'sharp' or 'stabbing') (40).

Fanaroff et al.'s 2015 systematic review (22) found that 'typical' chest pain had a non-helpful LR of 1.9, and that pain described as 'burning' had a similarly unhelpful LR of 1-1.4. More usefully, an older study (41) found that pain that was similar to a patient's previous AMI pain was suggestive of ACS in ANTCP and Fanaroff et al. (22) gave it a LR of 2.2 the second highest $L R$ for a chest pain characteristic (next to radiation to both arms).

Helpfully, the pattern of change in pain that a patient reports is also potentially useful. Pain that has changed in pattern over 24 hours has a LR of 2.0. However, pain that is worse with exertion is less helpful, having a LR of 1.5-1.8. Recent episodes of similar pain yield a LR of 1.3. Abrupt onset pain [LR 1.1] and associated palpitations [LR 0.71 ] are similarly unhelpful.

Interestingly, pain that is described as 'pleuritic' (usually meaning that it is associated with spontaneous ventilation) starts to come close (but not quite close enough to be definitive) to helping rule out ACS, with a LR of $0.35-0.61$. Pain that is reproduced by palpation gives the lowest $L R$ of all pain descriptors [0.28], also approaching (but not quite reaching) the borderline of becoming useful as a negative indicator.

As helpful as descriptions of pain could potentially be, subjectivity, vocabulary and cultural differences can complicate this assessment. For example, some cultures consider the word 'sharp' to mean 'severe' rather than 'pointed' or 'knife-like' (42). Furthermore, patients with peripheral neuropathologies may report atypical pain or no pain at all. The elderly, those who are diabetic and those with peripheral neuropathies may present atypically (43-46). (See also the description of the differences in reported quality of pain between men and women later in this paper.) 
Swap (47) suggests a useful aid memoire for signs that lean towards ruling out ACS in ANTCP, advising clinicians to remember that pain that displays the $3 \mathrm{Ps}$ (pleuritic, positional and palpable) is less likely to be of cardiac origin. He reports the following LRs for pain described as pleuritic [0.2], positional [0.3], and reproduced with palpation [0.3]. Fanaroff et al.'s 2015 systematic review (22) gave pain that was reproduced by palpation a slightly lower $L R$ of 0.28 . Pain that was described as 'sharp' had a LR of 0.3 and pain that was not associated with exertion had a LR of 0.8 . These findings lean (quite weakly) towards ruling out ACS in ANTCP.

\section{Location of pain}

Arm and chest pain is more common in ACS patients than nonACS patients (48) but cardiac pain rarely manifests below the navel or above the mandible (49) (the so-called 'nose to navel' region). There is no specific area on the torso that has a useful LR for ruling in or ruling out ACS. If a patient has pain between the umbilicus and upper mandible, it could be ACS. Anywhere else and it's less likely to be ACS.

\section{Radiation of pain}

Different studies have given different LRs for the radiation pattern of pain, but few go above 5 , so there is little profit in trying to determine the exact pattern a patient may be experiencing. The most recent systematic review by Fanaroff et al. (22) described the LRs of pain radiating to both arms as 2.6, pain radiating to the neck or jaw as 1.5 , and pain radiating to either the left arm or the right arm at 1.3.

Interestingly, two studies that were reviewed assessed what was described only as 'typical' chest pain (which one would assume used Heberden's definition) as ranging from an unhelpful LR of 1 to a moderately helpful 5.7. How should a clinician interpret this?

Any non-traumatic 'nose to navel' pain that radiates at all, in any way (ie. to one or both arms, or to the neck or jaw) should make the wary clinician more suspicious of ACS. The specific patterns of radiation are less important than its presence, so clinicians shouldn't waste too much time getting details. The clinical question of value is simply, 'Does the pain radiate or not'? If so, ACS is more likely.

\section{Intensity of pain}

It is a not-uncommon teaching that the pain of myocardial ischaemia is worse than most other causes of chest pain, and that the pain of an AMI is, in turn, worse than that of angina or atypical chest pain. Therefore clinicians routinely ask patients to rate their pain; usually on a scale of $0-10$.

However, there is no evidence to suggest that increased pain correlates with increased likelihood of cardiac pathology. A 1994 study (50) comparing pain in patients with ACS versus
non-ACS found no significant differences. Although it is an older study, one can presume that the presentation of chest pain hasn't altered dramatically in humans in just two decades and more recent studies $(51,52)$ have found that pain intensity is not useful diagnostically in assessing ACS (other than for titrating analgesia). One study (53) measured the predictive value of pain intensity for AMl when assessed in the out-of-hospital setting and concluded that 'the severity of chest pain is not a useful diagnostic criterion for AMl'.

It is important to stress that although the intensity of pain does not help to rule ACS in or out, it is an important symptom to monitor and to address therapeutically. There are many beneficial effects of pain reduction and appropriate analgesia remains an essential goal in the treatment of the patient with ANTCP.

\section{Ethnicity}

Although different ethnicities have different predilections to ACS, the presentation of patients in the acute setting does not vary significantly (54). Therefore ANTCP should be assessed similarly, regardless of the patient's ethnicity (55).

\section{0. 'Associated symptoms': nausea, vomiting and sweating} Another not-uncommonly encountered teaching is that nausea, vomiting and sweating - which are often collectively referred to as 'associated symptoms' (despite two of them being signs) - is suggestive of ACS. Evidence refutes this $(56,57)$. The LR for nausea and vomiting is only $0.92-1.1$ and the LR for sweating is a similarly unhelpful 1.3-1.4 (22).

Nausea, vomiting and sweating are indicators of sympathetic stimulation, and can give the clinician a proximate indicator that their patient is either scared or in pain, but being scared doesn't mean that a patient is experiencing ACS and, as previously shown, neither does having pain.

Once again, this is no reason to withhold anti-emetic therapy from patients. Paramedics should still treat nausea, when appropriate, but they shouldn't use its presence, absence, or intensity as a diagnostic clue to help rule in, or out, ACS in the ANTCP patient.

\section{Dyspnoea}

Shortness of breath (SOB) is another sign (or symptom) that is often thought to correspond with ACS. However, research has shown that SOB is more common in non-ACS than ACS patients (48) and has a non-useful LR of 1.2 (22).

\section{Dizziness}

Similar to SOB, dizziness has been found to be more common in non-ACS than ACS patients. Pelter et al. (48) and Fanaroff et al. (22) report a LR for syncope of 0.55 . This is yet another assessment that is of little discriminatory value. 
Colbeck: Paramedic diagnosis of acute coronary syndrome Australasian Journal of Paramedicine: 2016;13(4)

\section{Gender}

Although there have been studies that show differences in how men and women present in ACS, chest pain still continues to be the most commonly reported symptom in both genders (58).

However, women are less likely to report chest pain and sweating than men, and more likely to display a wider range of symptoms notably fatigue, neck pain, syncope, right arm pain, dizziness and jaw pain (59). Women with AMl are typically $6-10$ years older than men with AMl and are more likely to have a history of congestive heart failure (59). The Coventry et al. systematic review (59) on gender differences in symptom presentation is an excellent and modern review for those who want more detail, but the pertinent message is that men and women both complain of chest pain, and clinicians should be sensitive to a wider range of symptoms in women that suggest ACS.

\section{Physical examination}

Just as there is no particular symptom that unequivocally rules ACS in or out in ANTCP, there is also no clinical sign, or constellation of signs, that can secure the diagnosis. Of course signs of haemodynamic instability (cardiogenic shock and pulmonary oedema) are indicators of cardiac insufficiency and indicate a patient in distress and must be attended to regardless of the underlying diagnosis.

Common signs associated with ACS have also been assessed for their LR, but few have much predictive power. Hypotension has a LR of 3.9, similarly lung crackles [2.0], tachypnea [1.9], and tachycardia $>120$ [1.3] have weak discriminative power (22). Effectively treating these findings still remains an important therapeutic goal, but they are not diagnostically definitive.

Several other causes of chest pain do present with different signs than ACS and these should be assessed in the ANTCP patient. Note that the presence of signs which strongly suggest other pathophysiological processes (such as the characteristic rash of shingles) do not rule out ACS. It is possible to have both ACS and shingles (or other diseases) concurrently.

Pulmonary or mediastinal injuries can present with thoracic subcutaneous emphysema. Shingles present with a unilateral rash that follows dermatomes. Aortic aneurysms can present with unequal brachial blood pressures, pulsatile abdominal masses or, occasionally, a radio-femoral pulse transmission delay.

Tension pneumothorax can present with jugular venous distention, decreased levels of awareness, SOB, hypotension, tachycardia, a hyper-resonant and hyper-inflated unilateral (or bilateral) chest wall and (as a very late sign) a deviated trachea. Pulmonary embolism can present with tachycardia and haemoptysis, as well as the S1Q3T3 pattern on 12-lead ECG, although these are all relatively rare findings.

Pericarditis can present with positional characteristics (pain relieved when leaning slightly forward), concomitant signs of infection, and characteristic 12-lead changes (widespread concave ST elevation and PR depression throughout most of the limb leads (I, II, III, aVL, aVF) and precordial leads (V2-6); reciprocal ST depression and PR elevation in lead aVR ( \pm V1)) (60).

In addition, some clinicians have noted characteristic gestures that patients make when describing their ANTCP and have assessed whether they could be predictive on ACS. The most commonly described are: Levine's sign (a clenched fist); the palm sign (a flat palm held to the chest); the arm sign (touching the left arm); and the pointing sign (pointing to the pain with one finger).

A 2002 prospective observational study assessed for these signs in 202 patients presenting to an ED with ANTCP (61). The authors found that the signs had poor predictive value for ACS, though larger areas of pain were suggestive of ischaemia. The pointing sign had high specificity (98\%) for non-ischaemic chest pain, but a low prevalence; so if a clinician notices a spontaneously offered pointing sign, this would be a red flag (although this would be rare). See Table 1 'Summary of common physical exam components'.

\section{ECG changes}

A description of 12-lead ECG interpretation is beyond the scope of this article. However, performing a 12-lead ECG on any patient with ANTCP is an important standard of practice, and interpretation has been found to provide almost as much information as patient history factors combined $(62,63)$. Electrographic signs of infarct, bundle branch block or hypertrophy give a LR of only around 1.47 . Ischaemic ST depression gives a LR of 6.79 (12). Observing indicative changes in a series of ECGs yields a LR of 23.28 - a confidently strong 'rule in' score, second only to troponin measurements in terms of discriminative value.

However, there are significant perils to the 12-lead ECG that clinicians need to be aware of that make taking a patient history remain an essential part of a comprehensive assessment - $20 \%$ of AMl and $40 \%$ of unstable angina patients have normal ECGs on first recording (64). The initial 12-lead ECG has a sensitivity of only $20-60 \%$ for AMI (47) and a negative ECG does not rule out ACS, even if it is taken while the patient is having chest pain (65).

ECGs are also relatively insensitive at detecting transient myocardial ischaemia (66) ischaemia in patients with prior AMI (67) or ischaemia in the area of the left circumflex artery (68).

\section{Troponin}

A baseline troponin measurement of greater than three times normal gives a rather astounding LR of 58.92 - the single highest $L R$ in diagnosing ACS in ACNTCP, and clearly an unequivocal 'rule in' value. A change $>+0.3 \mathrm{ng} / \mathrm{mL}$ over 2 hours gives a similarly unequivocal LR of 25.07 (12). 


\begin{tabular}{|c|c|}
\hline \multicolumn{2}{|c|}{ Summary of common physical examination components } \\
\hline Assessment & $\begin{array}{l}\text { LR (when known) } \\
\text { or potential clinical } \\
\text { significance }\end{array}$ \\
\hline Hypotension & 3.9 \\
\hline Crackles (rales) on auscultation & 2.0 \\
\hline Tachypnea & 1.9 \\
\hline Tachycardia >120 & 1.3 \\
\hline Altered levels of awareness & Cerebral hypoxia \\
\hline Pale, cool, diaphoretic skin & $\begin{array}{l}\text { SNS stimulation, } \\
\text { shock }\end{array}$ \\
\hline Signs of infection & Concomitant infection \\
\hline Haemoptysis & $\begin{array}{l}\text { Pulmonary oedema } \\
\text { tuberculosis }\end{array}$ \\
\hline Jugular venous distension & $\begin{array}{l}\text { Central obstructive } \\
\text { process (tamponade), } \\
\text { fluid overload }\end{array}$ \\
\hline Deviated trachea (by palpation) & $\begin{array}{l}\text { Tension } \\
\text { pneumothorax }\end{array}$ \\
\hline Hyper resonant/inflated chest wall & $\begin{array}{l}\text { Tension } \\
\text { pneumothorax } \\
\end{array}$ \\
\hline Thoracic subcutaneous emphysema & $\begin{array}{l}\text { Tension } \\
\text { pneumothorax } \\
\text { Pneumomediastinum } \\
\text { Trauma } \\
\end{array}$ \\
\hline $\begin{array}{l}\text { Unilateral rash along thoracic derma- } \\
\text { tomes }\end{array}$ & $\begin{array}{l}\text { Varicella-zoster virus } \\
\text { ('Shingles') }\end{array}$ \\
\hline Unequal brachial blood pressures & $\begin{array}{l}\text { Subclavian steal } \\
\text { subse-quent to aortic } \\
\text { aneurysm }\end{array}$ \\
\hline Pulsatile abdominal masses & $\begin{array}{l}\text { Abdominal aortic } \\
\text { aneurysm }\end{array}$ \\
\hline $\begin{array}{l}\text { Radio-femoral pulse transmission } \\
\text { delay }\end{array}$ & $\begin{array}{l}\text { Abdominal aortic } \\
\text { aneu-rysm }\end{array}$ \\
\hline Ascities/Anasarca, Peripheral edema & $\begin{array}{l}\text { Heart failure, liver } \\
\text { failure }\end{array}$ \\
\hline Clubbing of digits & Chronic hypoxemia \\
\hline
\end{tabular}

Table 1. A summary of common components of the physical exam for patients with ANTCP

Clearly, troponin is a useful biomarker. Could it be used by paramedics? Research has addressed this question and found that pre-hospital measurement of troponin $T(T n T)$ is feasible, and it has a high success rate. One trial suggested that paramedic assessment of $\mathrm{TnT}$ could identify most patients with AMl irrespective of ECG changes (69).

\section{Putting it all together so far}

Many of the assessments paramedics regularly evaluate in the field are of no discriminative value in diagnosing ACS in the ANTCP patient (Table 2).

\begin{tabular}{|c|c|}
\hline \multicolumn{2}{|c|}{$\begin{array}{l}\text { Assessments of little or no discriminatory value in } \\
\text { diagnosing ACS in the ANTCP patient }\end{array}$} \\
\hline Assessment & $\begin{array}{l}\text { LR } \\
\text { (when known) }\end{array}$ \\
\hline \multicolumn{2}{|l|}{ Risk factors: } \\
\hline Hyperlipidemia & 1.3 \\
\hline Hypertension & 1.2 \\
\hline Any tobacco use & 1.1 \\
\hline Obesity & 1.0 \\
\hline Prior CABG & 0.97 \\
\hline Three to six risk factors & 1.4 \\
\hline No risk factors & 0.5 \\
\hline Patient response to GTN & 1.1 \\
\hline Gender (being male) & 1.3 \\
\hline Ethnicity & - \\
\hline 'Typical' ischaemic chest pain & 1.9 \\
\hline ‘Burning' pain & $1.0-1.4$ \\
\hline Worse with exertion & $1.5-1.8$ \\
\hline Recent similar episodes & 1.3 \\
\hline Abrupt onset & 1.1 \\
\hline Palpitations & 0.71 \\
\hline Location of pain & - \\
\hline \multicolumn{2}{|l|}{ Radiation of pain: } \\
\hline Both arms & 2.6 \\
\hline Neck/jaw & 1.5 \\
\hline Either or both arms & 1.3 \\
\hline Intensity of pain & - \\
\hline \multicolumn{2}{|l|}{ Associated symptoms: } \\
\hline Nausea & $0.92-1.1$ \\
\hline Vomiting & $0.92-1.1$ \\
\hline Sweating & $1.3-1.4$ \\
\hline Shortness of breath & 1.2 \\
\hline \multicolumn{2}{|l|}{ Gestures } \\
\hline $\begin{array}{l}\text { Palm sign, Levine sign, arm sign, } \\
\text { pointing sign }\end{array}$ & $\begin{array}{c}\text { Pointing sign is } \\
98 \% \text { specific, but } \\
\text { very rare }\end{array}$ \\
\hline Hypotension & 3.9 \\
\hline Tachypnea & 1.9 \\
\hline Tachycardia (>120) & 1.3 \\
\hline
\end{tabular}

Table 2. Assessments of little or no discriminatory value in diagnosing ACS in the ANTCP patient 
Table 3 presents and compares four assessment acronyms that are commonly taught to paramedic students to assess the ANTCP patient in order to determine if ACS may be present. As the above discussion details, these are almost all inefficient. Of the 10 assessments (left column) that are taught, only one (radiation) has a LR that approaches usefulness. Therefore, it is time for a new evidence-based assessment acronym that is efficient and effective.

The RSVP ${ }_{3}$ acronym, presented here for the first time in Table 4, has three evidence-based assessments (RSV) that suggest ACS and three evidence-based assessments $\left(P_{3}\right)$ that suggest that the patient is not experiencing ACS.

It's absolutely critical - for both the safety of paramedics and their patients - to keep two important things in mind. The first is that the likelihood ratios of these findings are very clearly in the 'moderately helpful' to 'not helpful' ranges, so it would be 'clinically adventurous' to put great faith in them. Although they are better than what has traditionally been taught (as they are evidence-based), the evidence is not strong.

The second important caveat is that although this is an accurate reflection of what the research has shown to be true, as a decision rule the RSVP ${ }_{3}$ acronym has not been clinically studied or validated in any way. The $\mathrm{RSVP}_{3}$ acronym is meant to summarise what has been discussed in the literature in a way that is understandable and easy to memorise, not to prescribe that this information is in any way a replacement for one's current practice. As always, paramedics should rely on their training, experience, practice guidelines and 'clinical gestalt' to make their own opinions. Determining an ANTCP patient to have a low likelihood of ACS is an important, but difficult, call to make and only the attending paramedic - in the context of a particular clinical situation - can make it.

\section{Perhaps it's time to put some 'HEART' into our ANTCP assessment?}

The RSVP ${ }_{3}$ aide memoire is meant to be of help while taking a patient history, but the patient history is only one part of a comprehensive patient examination. Research offers a comprehensive and effective way for paramedics to organise the other important factors in assessing a patient with ANTCP.

The HEART score (70) is a diagnostic risk stratification tool developed to help rule in or rule out ACS in ANTCP. It was developed by a senior cardiologist in The Netherlands ( $\mathrm{Dr}$ Jacob Six) who realised during ward rounds that the way he taught his residents to remember the key factors in assessing a patient with ANTCP could be remembered using the word 'heart'.

\begin{tabular}{|l|l|l|l|l|}
\hline \multicolumn{1}{|c|}{ Assessment } & \multicolumn{1}{c|}{ CHEST PAIN ${ }^{72}$} & \multicolumn{1}{c|}{ DOLOR $^{72}$} & \multicolumn{1}{c|}{ SOCRATES $^{73}$} & \multicolumn{1}{c|}{ OPQRST $^{72,73,74}$} \\
\hline Onset & Commenced & Onset & Onset & Onset \\
\hline Risk factors & History & - & - & - \\
\hline Associated symptoms & Extra symptoms & $\begin{array}{l}\text { Other signs and } \\
\text { symptoms }\end{array}$ & Associated symptoms & - \\
\hline Radiation & Stays/radiates & - & Radiation & Radiation \\
\hline Progression & Timing & - & Time, course, duration & Time \\
\hline Location & Places & Location & Site & - \\
\hline Provokes & Alleviates & - & $\begin{array}{l}\text { Exacerbating/ relieving } \\
\text { factors }\end{array}$ & Provokes \\
\hline Palliates & Aggravates & Relief & & Palliates \\
\hline Severity & Intensity & - & Severity & Severity \\
\hline Quality & Nature & Description & Character & Quality \\
\hline
\end{tabular}

Table 3. Comparison of acronyms taught to paramedic students to assist with the assessment of acute, non-traumatic chest pain

In Six's formulation, the word HEART is an acronym of its components (much like APGAR is) that lists the five assessments he determined to be most important: History, EKG, Age, Risk factors, Troponin.

Unlike other common cardiology scoring tools such as TIMI, PURSUIT and GRACE, the HEART score was developed specifically to assess patients in the ED setting in order to rule in or rule out ACS and is calculated on admission data only (13). This means that it does not require several hours of time to elapse in order to take serial measurements - it is performed in one, relatively brief patient encounter; an encounter that would be no longer than the typical amount of time that paramedics usually spend with ANTCP patients.

Since its inception the HEART score has been studied and validated extensively. In their 2012 systematic review, Fanaroff et al. (22) reported it to be the single most effective clinical decision tool for diagnosing ACS in ANTCP patients. Furthermore, like the APGAR score, it is relatively easy to remember and calculate without external tools (see Table 5). 


\begin{tabular}{|l|l|c|l|}
\hline RSVP $_{3}$ history & Details & LR & Interpretation \\
\hline Assessment & $\begin{array}{l}\text { The pain/discomfort DOES radiate anywhere to the arms, } \\
\text { neck or shoulders }\end{array}$ & 2.6 & Suggests ACS \\
\hline $\begin{array}{l}\text { R } \\
\text { Radiation }\end{array}$ & $\begin{array}{l}\text { The pain/discomfort IS similar to previous ACS or AMl } \\
\text { episodes that the patient has experienced }\end{array}$ & 2.2 & Suggests ACS \\
\hline $\begin{array}{l}\text { S } \\
\text { Similar }\end{array}$ & $\begin{array}{l}\text { The pain/discomfort HAS had a variation in pattern over } \\
\text { the past 24 hours }\end{array}$ & 2.0 & Suggests ACS \\
\hline $\begin{array}{l}\text { V } \\
\text { Variation }\end{array}$ & $\begin{array}{l}\text { Pain that varies in synch with the ventilatory cycle or that } \\
\text { is reproduced by deep inspiration }\end{array}$ & 0.2 & Suggests not ACS \\
\hline $\begin{array}{l}\text { P (1) } \\
\text { Pleuritic }\end{array}$ & Pain that varies in synch with the patient's body position & 0.3 & Suggests not ACS \\
\hline $\begin{array}{l}P(2) \\
\text { Positional }\end{array}$ & $\begin{array}{l}\text { Pain that is reproducible by palpation over the area of } \\
\text { pain }\end{array}$ & 0.3 & Suggests not ACS \\
\hline $\begin{array}{l}\text { P }(3) \\
\text { Palpation }\end{array}$ & & & \\
\hline
\end{tabular}

Table 4. RSVP ${ }_{3}$ history

\begin{tabular}{l|l|}
\hline $\begin{array}{l}\text { HEART score } \\
\text { History }\end{array}$ & 2 \\
\hline Highly suspicious & 1 \\
\hline Moderately suspicious & 0 \\
\hline Slightly or non-suspicious & 2 \\
\hline ECG & 1 \\
\hline Significant ST depression & 0 \\
\hline Nonspecific repolarisation disturbance & \\
\hline Normal & 2 \\
\hline Age & 1 \\
\hline 65 or greater & 0 \\
\hline 45 or greater to 65 & 2 \\
\hline 45 or younger & \\
\hline Risk factors & 1 \\
\hline $\begin{array}{l}\text { Three or more risk factors, or, history of } \\
\text { atherosclerotic disease }\end{array}$ & 0 \\
\hline One or two risk factors & 2 \\
\hline No risk factors known & 1 \\
\hline Troponin & 0 \\
\hline Three (or more) times the normal limit & \\
\hline $\begin{array}{l}\text { Greater than one to less than three times the normal } \\
\text { limit }\end{array}$ & 1 \\
\hline No greater than the normal limit & \\
\hline
\end{tabular}

\section{Table 5. HEART score}

Adapted from Six AJ, Backus BE, Kelder JC. Chest pain in the emergency room: value of the HEART score. Neth Heart J 2008;16:191-6.

A HEART score of 7-10 yields an impressive LR of 13 for ACS (22). This is a firm 'rule in' score. One prospective validation

study of 2440 patients presenting in 10 separate EDs revealed that low HEART scores [0-3] excluded short term MACE with $>98 \%$ certainty (71), which comes close to the $<1 \%$ error rate that legally wary physicians in the United States consider to be satisfactory.

Another study (72) had paramedics use the HEART score (using high sensitivity, point-of-care, qualitative troponin) to assess non-ST elevation patients with ANTCP. Patients were then followed up to determine their 30-day MACE rate. Remarkably, none of the patients with a HEART score less than 3 had an AMI. The caveat to this is that the number of patients in the study was low ( $n=207)$. Of the 42 patients (just over one-third from the study) assigned a HEART score of 3 or less, $93 \%$ were determined to have benign, non-cardiac chest pain. Two were suspected of having a supraventricular arrhythmia and one was suspected of having biliary colic. Of the $59 \%$ ( $n=73$ ) of patients in this study who were assigned an intermediate HEART score of 4-6, only two had an AMl and only one other had a 30-day MACE.

Based on these findings it could be reasonable for paramedics with the ability to evaluate pre-hospital troponin to choose to transport patients with a HEART score of $0-3$, and without signs of other significantly compromising (non-ACS) pathology, without the use of lights and sirens, or even to potentially refer these patients on to lower acuity, community resources instead of transporting them to an ED. Of course, more robust research would need to be conducted before this could be a firmly supported recommendation.

It would be beneficial to conduct a higher power trial to validate the use of the HEART score by paramedics. Performing such a study in order to improve the ability to safely and appropriately care for ANTCP patients is an important next step in advancing the care of these patients. Additional study to assess the utility of each element in a formal physical exam (for example, 
bilateral BPs, or the pointing sign) would allow paramedics to rationalise and streamline the physical examination of the ANTCP patient. Currently, best evidence suggests that the 'RSVP ${ }_{3}$ HEART exam', as outlined below in Figure 2, is the most efficient and effective way to differentiate between ACS and non-ACS presentations in the acute, non-traumatic paramedic patient with chest pain.

\section{Conclusion}

The assessment of the ANTCP patient in an attempt to differentiate between a high and a low risk for ACS is an ongoing clinical challenge. Much that is commonly taught to be of use in assessing a patient has been shown by robust analysis to have limited or no value. Spending time evaluating non-diagnostic criteria contravenes our mandate to rapidly and effectively evaluate patients.

There is no single factor that can clearly rule out ACS in the ANTCP patient, though positive 12-lead ECG and troponin findings provide strong evidence. The patient history provides a weaker level of evidence.

Attempts to aggregate factors to create a diagnostic scoring tool to stratify potential ACS patients have been ongoing. Of these, the HEART score using high sensitivity, point-ofcare, qualitative TnT testing has shown the most success in paramedic use, though further studies are needed to validate it.

The evidence-based clinician should focus their history (the
'H' in the HEART score) on the highest yield findings, which have been summarised in this paper with the novel acronym 'RSVP ', and avoid assessments that have been shown to be of little discriminative value. An organised and concise physical examination is also of critical value. Therefore this paper presents and recommends the use of the 'RSVP ${ }_{3}$ HEART Exam' mnemonic in the paramedic assessment of patients with ANTCP as a guide in the diagnosis of ACS.

Based on the existing literature it would be of benefit to study the RSVP ${ }_{3}$ HEART Exam pre-hospitally with a large, robustly powered study. The author encourages Australasian paramedics, academics and ambulance services to consider such a study as a part of their research agenda.

As a final and critical point, it cannot be emphasised strongly enough that there is no existing tool - including the one presented here - that can definitively rule out ACS in the outof-hospital patient.

The RSVP ${ }_{3}$ HEART Exam tool will help guide a clinician to perform their assessment of the ANTCP patient according to the best known evidence, but it could be fatally dangerous to assume that it is able to reliably and consistently produce a definitive 'rule out' of acute coronary syndrome.

\section{Acknowledgement}

The author wishes to thank Lesa Myers for her work in assisting with the editing of this paper.

\section{RSVP $_{3}$ HEART Exam}

\begin{tabular}{|c|c|c|}
\hline $\mathrm{H}$ & - History $\left(\mathrm{RSVP}_{3}\right)$ & + Radiation LR=2.6 \\
\hline $\mathrm{E}$ & $\bullet+$ ECG (series) LR=23 & $\begin{array}{l}\text { + Variation } \quad L R=2.0 \\
\text { - Pleuritic } \quad L R=0.2\end{array}$ \\
\hline A & - Age & - Palpation LR=1.3 \\
\hline $\mathbf{R}$ & - Risk Factors & $\begin{array}{l}\text { Peripheral Artery Disease } \quad L R=2.7 \\
\text { Coronary Artery Disease } \quad L R=2.7\end{array}$ \\
\hline $\mathrm{T}$ & $\bullet+$ Troponin LR=59 & Hypotension $\quad L R=3.9$ \\
\hline Exam & - Physical Exam & $\begin{array}{ll}\text { Tachypnoea } & \mathrm{LR}=2.7 \\
\text { Heart Rate }>120 & \mathrm{LR}=1.3\end{array}$ \\
\hline
\end{tabular}

Figure 2. Summary of recommendations for paramedic diagnosis of ACS in the ANTCP patient - the 'RSVP3 HEART Exam' 


\section{Conflict of interest}

The author declares he has no competing interests. The author of this paper has completed the ICMJE conflict of interest statement.

\section{References}

1. Nichols M, Peterson K, Alston L. 2014. Australian heart disease statistics. National Heart Foundation of Australia. Available at: https://heartfoundation.org.au/images/uploads/ publications/HeartStats_2014_web.pdf

2. Australian Institute of Health and Welfare. 2014. Healthcare expenditure on cardiovascular diseases 2008-2009. Available at: www.aihw.gov.au/WorkArea/DownloadAsset. aspx?id=60129546379

3. Fineberg HV, Scadden D, Goldman L. Care of patients with a low probability of acute myocardial infarction. Cost effectiveness of alternatives to coronary-care-unit admission. N Engl J Med 1984;310:1301-7.

4. Keeley EC, Hillis LD. Primary PCI for myocardial infarction with ST-segment elevation. N Engl J Med 2007;356:47-54.

5. Keeley EC, Boura JA, Grines CL. Primary angioplasty versus intravenous thrombolytic therapy for acute myocardial infarction: a quantitative review of 23 randomized trials. Lancet 2003;361:13-20.

6. McNamara RL, Wang Y, Herrin J, et al. Effect of doorto-balloon time on mortality in patients with ST-segment elevation myocardial infarction. J Am Coll Cardiol 2006;47:2180-6.

7. Nallamothu B, Fox K, Kennelly B, De Werf F, Gore J, Steg P. Relationship of treatment delays and mortality in patients undergoing fibrinolysis and primary percutaneous coronary intervention. The Global Registry of Acute Coronary Events. Br Heart J 2006;93:1552-5.

8. Maguire BJ, O'Meara PF, Brightwell RF, O'Neill BJ, Fitzgerald GJ. Occupational injury risk among Australian paramedics: an analysis of national data. Med J Aust 2014;200:477-80. http://doi.org/10.5694/mja13.10941

9. Lee CP, Uk M, Medicine MI, et al. Advances Emergency physician estimates of the probability of acute coronary syndrome in a cohort of patients enrolled in a study of coronary computed tomographic angiography. CJEM 2012;14:147-56. http://doi.org/10.2310/8000.2012.110485

10. Cahan A, Gilon D, Manor O, et al. Clinical experience did not reduce the variance in physicians' estimates of pretest probability in a cross-sectional survey. J Clin Epidemiol 2005;58:1211-6. doi:10.1016/j.jclinepi.2005.02.014.

11. Hess EP, Thiruganasambandamoorthy V, Wells G, et al. Diagnostic accuracy of clinical prediction rules to exclude acute coronary syndrome in the emergency department setting: a systematic review. CJEM 2008;10:373-82. doi:10.1016/j.jclinepi.2007.09.013

12. Fesmire FM, Martin EJ, Cao Y, Heath GW. Improving risk stratification in patients with chest pain: the Erlanger HEARTS3 score. Am J Emerg Med 2012;30:1829-37. http:// doi.org/10.1016/j.ajem.2012.03.017

13. Than M, Flaws D, Cullen L, Deely JM. Cardiac risk stratification scoring systems for suspected acute coronary syndromes in the emergency department. Curr Emerg Hosp Med Reports 2013;1:53-63. http://doi.org/10.1007/s40138012-0004-0

14. Than M, Herbert M, Flaws D, et al. What is an acceptable risk of major adverse cardiac event in chest pain patients soon after discharge from the emergency department. Int J Cardiol 2013;166:752-4. doi:10.1016/j.ijcard.2012.09.171.

15. Greene J. The perils of low-risk chest pain. Ann Emerg Med 2010;56:25A-8A.

16. Heberden W. Some account of a disorder of the breast. Medical Transactions 1772;2:59-67.

17. Eslick GD. Chest pain: a historical perspective. Int J Cardiol 2001;77:5-11.

18. Newberry L, Barnett GK, Ballard N. A new mnemonic for chest pain assessment. J Emerg Nurs 2005;31:84-5. http:// doi.org/10.1016/j.jen.2004.10.005

19. Mitchell AM, Garvey JL, Chandra A, Diercks D, Pollack CV, Kline JA. Prospective multicenter study of quantitative pretest probability assessment to exclude acute coronary syndrome for patients evaluated in emergency department chest pain units. Ann Emerg Med 2006;47:447.

20. Høilund-Carlsen PF, Johansen A, Vach W, Christensen HW, Møldrup M, Haghfelt T. High probability of disease in angina pectoris patients: is clinical estimation reliable? Can J Cardiol 2007;23:641-7.

21. Panju AA, Hemmelgarn BR, Guyatt GH, Simel DL. The rational clinical examination: is this patient having a myocardial infarction? JAMA 1998;280:1256-63.

22. Fanaroff AC, Rymer JA, Goldstein SA, Simel DL, Newby LK. Does this patient with chest pain have acute coronary syndrome? JAMA 2015;314:1955. http://doi.org/10.1001/ jama.2015.12735

23. Body R, Carley S, Wibberley C, McDowell G, Ferguson $\mathrm{J}$, Mackway-Jones $\mathrm{K}$. The value of symptoms and signs in the emergent diagnosis of acute coronary syndromes. Resuscitation 2010;81:281-6. http://doi.org/10.1016/j. resuscitation.2009.11.014

24. Body R, Cook G, Burrows G, Carley S, Lewis PS. Can emergency physicians "rule in" and "rule out" acute myocardial infarction with clinical judgement? Emerg Med J 2014;31:872-6. http://doi.org/10.1136/ emermed-2014-203832

25. Bruyninckx R, Aertgeerts B, Bruyninckx P, Buntinx F. Signs and symptoms in diagnosing acute myocardial infarction and acute coronary syndrome: a diagnostic meta-analysis. Br J Gen Pract 2008;58:105-11. http://doi.org/10.3399/ bjgp08X277014

26. Grimes DA, Schulz KF. Refining clinical diagnosis with likelihood ratios. Lancet 2005;365:1500-5. http://doi. org/10.1016/S0140-6736(05)66422-7 
27. Hayden SR, Brown MD. Likelihood ratio: a powerful tool for incorporating the results of a diagnostic test into clinical decision making. Ann Emerg Med 1999;33:575-80.

28. Han JH, Lindsell CJ, Hornung RW, et al. The elder patient with suspected acute coronary syndromes in the emergency department. Acad Emerg Med 2007;14:732-9. http://doi. org/10.1197/j.aem.2007.04.008

29. Walker NJ, Sites FD, Shofer FS, Hollander JE. Characteristics and outcomes of young adults who present to the emergency department with chest pain. Acad Emerg Med 2001;8:703-8.

30. Marsan RJ, Shaver KJ, Sease KL, Shofer FS, Sites FD, Hollander JE. Evaluation of a clinical decision rule for young adult patients with chest pain. Ibid. 2005;12:26-31.

31. Christenson J, Innes G, McKnight D, et al. A clinical prediction rule for early discharge of patients with chest pain. Ann Emerg Med 2006;47:1-10.

32. Jalili M, Hejripour Z, Honarmand AR, Pourtabatabaei N. Validation of the Vancouver chest pain rule: a prospective cohort study. Acad Emerg Med 2012;19:837-42.

33. Body R, McDowell G, Carley S, Mackway-Jones K. Do risk factors for chronic coronary heart disease help diagnose acute myocardial infarction in the emergency department? Resuscitation 2008;79:41-5. http://doi.org/10.1016/j. resuscitation.2008.06.009

34. Dooley J, Chang AM, Salhi R, Hollander JE. Relationship between body mass index and prognosis of patients presenting with potential acute coronary syndromes. Acad Emerg Med 2013;20:904-10. http://doi.org/10.1111/ acem.12211

35. Henrikson CA, Howell EE, Bush DE, et al. Chest pain relief by nitroglycerin does not predict active coronary artery disease. Ann Intern Med 2003;139:979-86.

36. Shry EA, Dacus J, Van De Graaff E, Hjelkrem M, Stajduhar $\mathrm{KC}$, Steinhubl SR. Usefulness of the response to sublingual nitroglycerin as a predictor of ischemic chest pain in the emergency department. Am J Cardiol 2002;90:1264-6.

37. Diercks DB, Boghos E, Guzman H, Amsterdam EA, Kirk JD. Changes in the numeric descriptive scale for pain after sublingual nitroglycerin do not predict cardiac etiology of chest pain. Ann Emerg Med 2005;45:581-5.

38. Grailey K, Glasziou PP. Diagnostic accuracy of nitroglycerine as a "test of treatment" for cardiac chest pain: a systematic review. Emerg Med J 2012;29:173-6. http://doi.org/10.1136/ emj.2010.103994

39. Steele R, McNaughton T, McConahy M, Lam J. Chest pain in emergency department patients: if the pain is relieved by nitroglycerin, is it more likely to be cardiac chest pain? CJEM 2006;8:164-9.

40. Green GB, Hill PB. Chest pain: cardiac or not. In: Tintinalli J. Tintinalli's Emergency Medicine: A Comprehensive Study Guide. 2012, 7th edn. Sydney: McGraw-Hill.

41. Chun AA, McGee SR. Bedside diagnosis of coronary artery disease: a systematic review. Am J Med 2004;117:334-3.
42. Summers RL, Cooper GJ, Carlton FB, Andrews ME, Kolb $\mathrm{JC}$. Prevalence of atypical chest pain descriptions in a population from the southern United States. Am J Med Sci 1999;318:142-5.

43. Canto JG, Shlipak MG, Rogers WJ, et al. Prevalence, clinical characteristics, and mortality among patients with myocardial infarction presenting without chest pain. JAMA 2000;283:3223-9.

44. Caracciolo EA, Chaitman BR, Forman SA, et al; Asymptomatic Cardiac Ischemia Pilot Investigators. Diabetics with coronary disease have a prevalence of asymptomatic ischemia during exercise treadmill testing and ambulatory ischemia monitoring similar to that of nondiabetic patients: an ACIP database study. Circulation 1996;93:2097105.

45. Murray DP, O'Brien T, Mulrooney R, O'Sullivan DJ. Autonomic dysfunction and silent myocardial ischaemia on exercise testing in diabetes mellitus. Diabet Med 1990;7:580-4.

46. Richman PB, Brogan GX Jr, Nashed AN, Thode HC Jr. Clinical characteristics of diabetic vs nondiabetic patients who "rule-in" for acute myocardial infarction. Acad Emerg Med 1999;6:719-23.

47. Swap CJ. Value and limitations of chest pain history in the evaluation of patients with suspected acute coronary syndromes. JAMA 2005;294:2623. http://doi.org/10.1001/ jama.294.20.2623

48. Pelter MM, Riegel B, McKinley S, et al. Are there symptom differences in patients with coronary artery disease presenting to the ED ultimately diagnosed with or without ACS? Am J Emerg Med 2012;30:1822-8. http://doi. org/10.1016/j.ajem.2012.03.002

49. Rosen's Emergency Medicine: Concepts and Clinical Practice. Philadelphia, PA: Mosby/Elsevier; 2010.

50. Eriksson B, Vuorisalo D, Sylven C. Diagnostic potential of chest pain characteristics in coronary care. J Intern Med 1994;235:473-8.

51. Edwards M, Chang AM, Matsuura AC, Green M, Robey JM, Hollander JE. Relationship between pain severity and outcomes in patients presenting with potential acute coronary syndromes. Ann Emerg Med 2011;58:501-7. http:// doi.org/10.1016/j.annemergmed.2011.05.036

52. Body R, Lewis PS, Carley S, Burrows G, Haves B, Cook G. Chest pain: if it hurts a lot, is heart attack more likely? Eur J Emerg Med 2016;23:89-94. http://doi.org/10.1097/ MEJ.0000000000000218 53. Galinski M, Saget D, Ruscev M, et al. Chest pain in an out-of-hospital emergency setting: no relationship between pain severity and diagnosis of acute myocardial infarction. Pain Pract 2015;15:343-7. http://doi.org/10.1111/papr.12178

54. Johnson PA, Lee TH, Cook EF, Rouan GW, Goldman $L$. Effect of race on the presentation and management of patients with acute chest pain. Ann Intern Med 1993;118:593-601. 
55. Skinner JS, Smeeth L, Kendall JM, Adams PC, Timmis A. NICE guidance. Chest pain of recent onset: assessment and diagnosis of recent onset chest pain or discomfort of suspected cardiac origin. Heart 2010;96:974-8. http://doi. org/10.1136/hrt.2009.190066

56. Goodacre S, Locker T, Campbell S. How useful are clinical features in the diagnosis of acute, undifferentiated chest pain? Acad Emerg Med 2002;9:203-8. http://doi. org/10.1197/aemj.9.3.203

57. Kamali A, Söderholm M, Ekelund U. What decides the suspicion of acute coronary syndrome in acute chest pain patients? BMC Emerg Med 2014;14:9. http://doi. org/10.1186/1471-227X-14-9

58. Berg J, Björck L, Dudas K, Lappas G, Rosengren A. Symptoms of a first acute myocardial infarction in women and men. Gend Med 2009;6:454-462. http://doi. org/10.1016/j.genm.2009.09.007

59. Coventry LL, Finn J, Bremner AP. Sex differences in symptom presentation in acute myocardial infarction: a systematic review and meta-analysis. Heart Lung 2011:40:477-91. http://doi.org/10.1016/j.hrtlng.2011.05.001

60. Available at: http://lifeinthefastlane.com/ecg-library/basics/ pericarditis/ [Accessed 20 January 2016].

61. Marcus GM, Cohen J, Varosy PD, et al. The utility of gestures in patients with chest discomfort. Am J Med 2007;120:83-9. http://doi.org/10.1016/j.amjmed.2006.05.045

62. Lee TH, Goldman L: Evaluation of the patient with acute chest pain. N Engl J Med 2000;342:1187-95.

63. Goldman L, Kirtane AJ. Triage of patients with acute chest pain and possible cardiac ischemia: the elusive search for diagnostic perfection. Ann Intern Med 2003;139:987-95.

64. Pope JH, Selker HP: Diagnosis of acute cardiac ischemia. Emerg Med Clin North Am 2003;21:27-59.
65. Turnipseed SD, Trythall WS, Diercks DB, et al. Frequency of acute coronary syndrome in patients with normal electrocardiogram performed during presence or absence of chest pain. Acad Emerg Med 2009;16:495-9.

66. Sharkey S, Berger C, Brunette D, Henry T. Impact of the electrocardiogram on the delivery of thrombolytic therapy for acute myocardial infarction. Am J Cardiol 1994;73:550-3.

67. Wagner G. Marriott's Practical Electrocardiography. 11th edn. Wilkins LW, editor. Philadelphia: 2008, p. 145-62.

68. Zhou S: An automated algorithm to improve ECG detection of posterior STEMI associated with left circumflex coronary artery occlusion. Comput Cardiol 2006;33:33-6.

69. Sørensen JT, Terkelsen CJ, Steengaard C, et al. Prehospital troponin $\mathrm{T}$ testing in the diagnosis and triage of patients with suspected acute myocardial infarction. Am J Cardiol 2011;107:1436-40. http://doi.org/10.1016/j. amjcard.2011.01.014

70. Six AJ, Backus BE, Kelder JC. Chest pain in the emergency room: value of the HEART score. Neth Heart 2008;16:1916. http://doi.org/10.1007/BF03086144

71. Backus BE, Six AJ, Kelder JC, et al. A prospective validation of the HEART score for chest pain patients at the emergency department. Int J Cardiol 2013;168:2153-8. http://doi. org/10.1016/j.jijcard.2013.01.255

72. Ali D, Fokkert MJ, Slingerland R, et al. Feasibility of prehospital chest pain triage at home or in the ambulance by paramedics using the HEART score based upon a single high-sensitive troponin T analysis. Eur Heart J Published online 1 August 2013.

73. Curtis K, Ramsden C. Emergency and Trauma Care for Nurses and Paramedics. 2015. 2nd edn. Elsevier; Australia.

74. Sanders M, McKenna KD, Lewis LM, Quick G. Mosby's Paramedic Textbook, 2012. 4th edn. Elsevier; Australia. 